\title{
The Epidemiology and Prevention of Herpes Zoster
}

\author{
Harriet J. Forbes • Sara L. Thomas • Sinéad M. Langan
}

Published online: 18 January 2012

(C) Springer Science+Business Media, LLC 2012

\begin{abstract}
Herpes zoster is a common disease among older individuals, affecting approximately $25 \%$ of people in their lifetime and resulting in appreciable morbidity. The risk of zoster increases sharply with age and immunosuppression, yet relatively little is known about other risk factors for zoster. A vaccine for zoster is now available that holds the potential to reduce incidence of zoster and its complications. In this review, the recent literature on zoster incidence and potential risk factors for the disease are summarized. Current methods of preventing zoster and its associated morbidity are discussed, including zoster vaccine and the use of antivirals.
\end{abstract}

Keywords Shingles · Herpes zoster · Epidemiology · Incidence $\cdot$ Vaccine

\section{Introduction}

Herpes zoster is a common disease among older individuals, with a lifetime risk of $10 \%$ to $30 \%$ that rises to $50 \%$ among those living to $\geq 85$ years [ $1 \bullet$ ]. It is caused by the reactivation of latent varicella zoster virus (VZV), which can lie dormant for many decades after varicella (chickenpox) infection. Reactivation is thought to result from waning cellmediated immunity. Zoster typically presents as a painful unilateral vesicular dermatomal rash (Fig. 1) that causes acute morbidity lasting between 2 weeks and 1 month [2].

The most common complication of zoster is post-herpetic neuralgia (PHN), which develops in around $20 \%$ of

H. J. Forbes $(\bowtie) \cdot$ S. L. Thomas $\cdot$ S. M. Langan

Faculty of Epidemiology \& Population Health,

London School of Hygiene and Tropical Medicine,

Keppel Street,

London WC1E 7HT, UK

e-mail: Harriet.forbes@1shtm.ac.uk individuals aged $\geq 50$ years [3]. PHN is often defined as pain persisting for $>90$ days after the onset of the rash; the pain can be very severe and remain for years [4]. Although zoster is rarely fatal, the pain associated with the acute phase of the disease and subsequent PHN significantly reduces quality of life [5]. Other rarer complications of zoster, such as cranial and peripheral nerve palsies [6], encephalitis and myelitis [7], and stroke $[8,9]$, have been described but few data exist about the frequency and severity of these complications.

There are two main reasons to present an update of the epidemiology and prevention of zoster. Firstly, zoster predominantly affects older populations, and with an increasingly aging population, it is likely to become increasingly common. Secondly, a vaccine to prevent zoster has recently been introduced for adult immunocompetent individuals in the United States and Australia, so this is an exciting era for zoster epidemiology and warrants increased research focus.

In this review, we summarize the literature on zoster, using key articles and reviews up to 2003 with more detailed investigation of recent research. We cover incidence of zoster and risk factors for the disease. Current methods for preventing zoster and its associated morbidity are discussed, including antivirals and the recently developed vaccine. Important unanswered clinical questions identified during the review are listed in Table 1.

\section{Epidemiology}

Incidence

Incidence in General Population

A systematic review published in 2004 found the overall incidence of zoster among immunocompetent subjects ranged from 1.2 to 4.8 per 1000 people per year [1•]; recent 


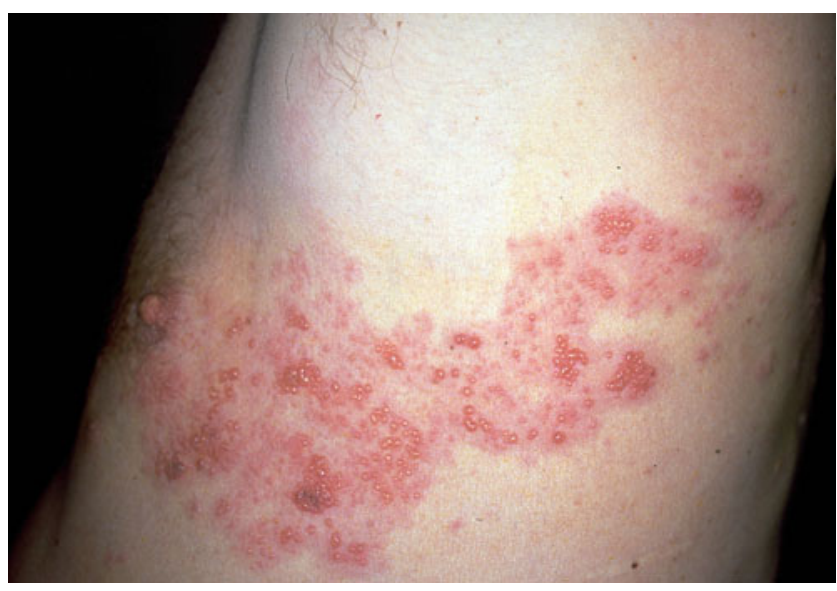

Fig. 1 Acute herpes zoster. (Courtesy of Professor Dr Thomas Diepgen, Heidelberg, Germany)

studies from the United States [10,11] and France [12] have also reported disease incidences within this range. The incidence of zoster increases markedly with age, with estimated incidences of up to 14.2 per 1000 people per year in those aged $\geq 50$ years in the United States [1•], the United Kingdom [3], Italy [13], and Germany [14].

\section{Incidence Among Immunosuppressed}

The incidence of zoster among people with a generalized loss of cell-mediated immunity either from immunosuppressive disorders, such as HIV and cancer, or from the use of immunosuppressive therapies is much higher than in the general population, with incidence rates ranging from 14.5 to 53.6 per 1000 person-years [15-20]. In a retrospective cohort study using the Veteran Affairs administrative databases in the United States, the rate of zoster following a solid organ transplant was estimated at 22 per 1000 person-years overall, with higher rates seen among African American patients (37.6 per 1000 person-years) and heart transplant patients (40 per 1000 person-years) [17].

The incidence of zoster among patients on biologic drugs is of interest due to the increased use of these drugs and their potential impact on cellular immunity. A retrospective cohort study in Israel among psoriasis patients found zoster incidence was higher among patients treated with biologics such as infliximab (19.1 per 1000-person-years) compared to patients not on systemic therapy (4.6 per 1000 personyears) [21], but the difference in incidence did not reach statistical significance. Data from registries of patients with rheumatic diseases treated with biological agents in Spain [22], Germany [23], and France [24] suggest an increased risk of zoster when these patients are treated with monoclonal antibody-tumor necrosis factor (TNF) inhibitors. However residual confounding may contribute to these findings. A longitudinal study from the United States of patients in the National Data Bank for Rheumatic Diseases found biologics were not a risk factor for zoster [25], whereas a retrospective cohort study using an American administrative data source of people with rheumatoid arthritis reported those taking biologic therapy were at higher risk of zoster (adjusted odds ratio [OR] 1.54; 95\% CI, 1.04-2.29) compared to patients not taking disease-modifying drugs or corticosteroids (but those taking oral corticosteroids were at even higher risk (adjusted OR 2.51; 95 CI, 2.05-3.06)) [26]. Disentangling risk associated with disease severity and impact of therapy remain challenging.

\section{Recurrent Incidence}

It is widely believed that second episodes of zoster are very uncommon, except among immunosuppressed individuals for whom recurrent zoster is well described. Therefore, a surprising finding from a recent population-based, retrospective cohort study in Minnesota was that of 1530 individuals diagnosed with zoster and deemed "immunocompetent" at the time of diagnosis, a second zoster episode was recorded in $5.7 \%$ in the subsequent 8 years [27]. Misclassification of immune status is possible in this study: immune status was determined only at the time of the first zoster episode and individuals with HIV infection who had not yet developed AIDS-defining illnesses and those taking low doses of systemic corticosteroids $(<5 \mathrm{mg} / \mathrm{d}$ ) were deemed immunocompetent. Thus, the immunocompetent group may have included some individuals with moderate immunosuppression at baseline as well as some who became immunosuppressed during follow-up [27, 28]. In addition, a small proportion of the clinically diagnosed zoster cases could have had herpes simplex rather than zoster. Research using larger datasets and more detailed characterization of immune status over time would be useful to confirm these findings. As expected in

Table 1 Unanswered questions

What is the risk of zoster among older patients with specific co-morbidities?

Can newer antiviral agents, such as famciclovir and valacyclovir, reduce the duration and severity of post-herpetic neuralgia?

What is the absolute risk of zoster directly related to treatment with biologic medications?

What approach should clinicians take regarding interruption of therapy in patients receiving biologics to administer the live zoster vaccine? 
the Minnesota study, risk of recurrent zoster was almost three times higher among the 139 immunosuppressed patients compared to those classified as immunocompetent (hazard ratio [HR] 2.80; 95\% CI, 1.84-4.27).

\section{Temporal Changes in Incidence}

Despite an expectation that aging populations and increasing use of immunosuppressive therapies during the course of the 20th century could have caused an increase in occurrence of zoster, reports of temporal changes in zoster incidence are conflicting [1•]. Interest in trends in zoster incidence over time heightened after the introduction of the varicella vaccine because of concerns that by removing exogenous boosting of VZV immunity from varicella contacts [29], zoster incidence could rise among older unvaccinated individuals with latent VZV infection [30].

Varicella vaccine became available in the United States in 1995 for healthy children aged over 12 months, susceptible adolescents, and adults. Vaccine uptake in the United States was slow during the first 5 years but increased from $68 \%$ in 2000 to $89 \%$ in 2006 among 19- to 35 - month-old children [31]. Studies of the impact of introduction of the varicella vaccine on zoster incidence have shown inconsistent findings. Jumaan et al. [32] report no increase in zoster incidence between 1993 and 2002 among patients enrolled with a health insurance organization in Washington state [32]. In contrast, two further US studies report increases in zoster incidence rates following varicella vaccination. A telephone survey in Massachusetts found an increase in zoster incidence from 2.77 to 5.25 cases per 1000 people between 1999 and 2003 [33]. A study using the Veterans Administration database reported that between 2000 and 2007 (when vaccine coverage was higher), zoster increased from 3.10 to 5.22 episodes per 1000 people aged $\geq 40$ years, although rates per year were not standardized for age [34]. Interpretation of the impact of the vaccine on zoster also has to consider background trends in zoster incidence. A further US study described greater increases in zoster incidence rates before varicella vaccine licensure compared to post-licensure periods, although interpretation was complicated by exclusion of Medicare enrollees (ie, older individuals receiving Medicare health insurance) from the earlier estimate [31]. As most older individuals in the US are enrolled in Medicare and the majority of zoster episodes occur in this age group, the true incidence rates may be distorted. Increases in zoster incidence prior to varicella vaccine introduction have also been described in Canada [35], Australia [36], and Spain [37]. Whether population-based varicella vaccination affects zoster incidence remains controversial.

\section{Risk Factors for Herpes Zoster}

Any factor impacting on VZV-specific or general cellmediated immunity may affect risk of zoster. However, beyond the two key risk factors of age and immunosuppression, relatively little is known. Potential risk factors for zoster are outlined below.

Factors Affecting General Cell-Mediated Immunity

Age

The most important risk factor for zoster is increasing age, with incidence rates rising among older individuals (see above). This is likely to be due to immunosenescence (the generalized waning of cell-mediated immunity over the life course), which puts individuals at greater risk of many infections [38], as well as waning of VZV-specific immunity with increasing time since primary infection.

\section{Immunosuppression}

As discussed in the section on zoster incidence, the incidence of zoster among patients with immunosuppressive diseases is far greater than among the general population. Patients with HIV have up to 10 times the risk of developing zoster compared to the general population [18], and in specific young African populations, the positive predictive value (PPV) for underlying HIV infection when zoster is present is $85 \%$ to $90 \%[39,40]$. The PPV will vary depending on HIV prevalence in the population; reported PPVs of zoster for HIV vary from $3.7 \%$ in Brazil to $91 \%$ in a Ugandan study population [41, 42]. The risk of zoster is also markedly increased among those with leukemia, lymphoma, and metastatic malignancies and among those with selected autoimmune disorders, although disentangling immunosuppression related to disease pathology from immunosuppressive therapies for these conditions (discussed below) is challenging [15, 26, 43-47]. Recent studies have indicated that diseases associated with less marked immune suppression may also increase the risk of zoster. A retrospective hospital-based cohort study in Japan showed an increased risk of zoster among diabetic patients (HR 2.38; 95\% CI, 2.04-2.78) [48] as did a nested case-control study from Israel (OR 1.53; 95\% CI, 1.44-1.62) [49]. Chronic obstructive pulmonary disorder (COPD) has also been associated with increased risk of zoster, again possibly reflecting the therapies used [50]. Although the magnitude of the risk is smaller than among patients with severe immunosuppression, the high prevalence of common diseases means that the absolute number of people affected may be significant. 
Increased zoster incidence is also reported in specific highrisk groups with iatrogenic immunosuppression following treatment with cytotoxic drugs or therapies affecting the immune response. The increased risk of zoster identified among individuals with COPD or with autoimmune disorders such as rheumatoid arthritis, Wegener's granulomatosis, or systemic lupus erythematosus mentioned above may partly reflect use of corticosteroids or disease-modifying drugs. Recent observational data from a German and Spanish biologics registry has suggested additional increases in zoster incidence related to use of monoclonal drugs inhibiting TNF- $\alpha$ in rheumatoid arthritis treatment $[22,23]$, consistent with findings from randomized controlled trials and observational studies in large databases in the United Kingdom and United States. Findings from psoriasis biologic registries are awaited to identify the long-term effect of biologic therapies on zoster risk. Although the relative risk among people with major immunosuppression from specific diseases and/or therapeutic interventions is high, these individuals account for $<10 \%$ of cases with zoster in most population-based studies $[10,51]$ from Europe and North America.

\section{Gender}

Thomas and Hall's [1•] systematic review suggested that female sex may be a risk factor for zoster. Subsequent studies from the United States, United Kingdom, Italy, France, and Germany have reported significantly higher incidence rates among women $[3,10,12-14]$. It is unclear to what extent the reported increased incidence rates in women reflect a bias due to differences in health-seeking behavior as opposed to biological mechanisms affecting cell-mediated immunity that could put women at higher risk $[1 \bullet]$.

\section{Diet, Smoking, and Alcohol Use}

Diets low in micronutrients may increase zoster risk by diminishing cell-mediated immunity and hastening immunosenescence among older individuals. A UK case-control study found no association between intake of single micronutrients and risk of zoster; however, among individuals aged $\geq 60$ years, combined low micronutrient intake and low vegetable intake were associated with increased risk of zoster, as was lower fruit intake (at all ages) [52]. These results suggested that a mixture of nutrients in the diet may be necessary to maintain immune system health. Accurate measurement of micronutrient and diet intake is notoriously difficult; however, the study found strong dose-response associations that give credence to the findings.

Smoking and alcohol can affect cell-mediated immunity [53, 54], although no studies have been specifically designed to look at their effect on zoster risk. A cohort study in North Carolina found smoking was associated with a markedly lower risk of zoster [55], whereas another study using routine data from UK general practices from 1991 to 92 found no association between smoking and zoster risk [1•].

\section{Stress}

Stress may increase risk of zoster as it affects a number of neuroendocrine functions that can affect cell-mediated immunity [56]. A case-control study in North Carolina found stressful life events were more common in zoster cases within the 6 months prior to rash onset than in agematched controls ( 2.64 vs 1.82 events; $P=0.008$ ), although recall bias may have contributed to this finding [57]. Analyses of the same population using a cohort study design found some evidence that negatively perceived life events were weakly associated with risk of subsequent zoster (risk ratio [RR] 1.38; 95\% CI, 0.96-1.97), although the study lacked power to detect a significant effect [55]. A retrospective cohort study in Taiwan found patients with a psychiatric illness were more likely to have an episode of zoster (HR 1.29; 95\% CI, 1.18-1.38) [58], which may reflect increased stress among these patients.

Factors Affecting Varicella Zoster Virus-Specific Immunity

Age at Primary Infection

Individuals acquiring varicella later in life have been hypothesized to be at lower risk of zoster as their immunity to VZV may last to older ages. No published studies have looked at this hypothesis directly, but country of birth has been taken as a proxy for age at varicella infection. Typically, in temperate areas, varicella onset is during childhood, whereas onset is often delayed until adolescence or even adulthood in some tropical areas such as southern India, Sri Lanka, and the Caribbean. Late varicella acquisition has been suggested as the reason why people of black ethnicity in a US study of older individuals had around one third the risk of zoster compared with those of white ethnicity (OR 0.35; 95\% CI, 0.24-0.51) [55].

There is also some evidence that very early acquisition of varicella, in utero or in early infancy, may increase the risk of zoster during childhood and adolescence, perhaps because the immune system is not able to establish VZV immunity at such a young age [59].

\section{Varicella Contacts}

Hope-Simpson [29] hypothesized in 1965 that exposure to individuals with varicella could naturally boost VZV- 
specific immunity in individuals with latent VZV infection and thus could protect against zoster [29], leading to the concern, as outlined in the section on zoster incidence, that population-based varicella vaccination might lead to changes in the incidence of zoster. Hope-Simpson's theory has been supported by a UK population-based case-control study of incident zoster cases and age- and sex-matched controls. The study found increasing protection against zoster with increasing number of varicella contacts in the 10 years before zoster, and a similar association with child contacts (used as proxies for unrecognized varicella contacts) $[1 \cdot]$. In contrast, a recent US case-control study of individuals interviewed 2 months to 5 years after zoster diagnosis found no evidence that varicella contacts or child contacts protected against zoster [60]. Even participants with three or more varicella contacts over the past 10 years were not associated with a significantly increased risk of zoster compared with participants with no contacts (OR 1.37 ; 95\% CI, 0.82-2.27). However the incidence of varicella at the time of the US study was low in comparison to that in the UK study, due to the US population-based varicella vaccination program. Few participants in the US study had more than two contacts with varicella in the previous 10 years $(2 \%$ of controls compared with $17 \%$ of controls in the UK study), and some of these contacts could have been mild cases of breakthrough varicella in vaccinated children. Thus, participants in the US study perhaps had insufficient exposure to varicella to provide exogenous boosting.

\section{Other Risk Factors}

\section{Genetics}

The possibility of genetic susceptibility to zoster and its associated morbidity has some support from genetic association studies. Zoster cases in Finland and Korea were more likely to carry certain polymorphisms of the interleukin-10 gene, an immunomodulatory cytokine that suppresses cell-mediated immunity, compared to healthy controls [61, 62]. A study in Japanese zoster patients also found an association between human leukocyte antigens (HLA) haplotypes and PHN cases [63]. Two case-control studies using family history of zoster as an indicator for genetic susceptibility to zoster found opposing results. Hicks et al. [64] reported finding a family history of zoster more commonly among incident zoster cases in the United States compared to controls with other skin diseases, whereas Gatti et al. [65] found no difference in family history of zoster between cases with PHN and controls without a history of zoster presenting with hypertension in Italy. Further research is needed to clarify whether there is inherited susceptibility to zoster or to PHN among those who develop zoster.

\section{Mechanical Trauma}

Mechanical trauma has long been thought to be a risk factor for zoster, based largely on case reports. A case-control study published in 2004 found that mechanical trauma in the 6 months before rash onset was associated with an eightfold increased risk of zoster at the site of the trauma (OR 8.02; 95\% CI, 2.24-28.69), and trauma within 1 month before rash onset was associated with a 12-fold increased risk (OR 12.07; 95\% CI, 1.49-97.63) [66].

\section{Immunotoxin Exposure}

A cross-sectional study in the United States of people living close to a pesticide dump site found those living closer to the dump were more likely to report a history of zoster; however, the sequence between zoster events and residence near the dump was not ascertained [67].

\section{Prevention}

\section{Vaccine}

The zoster vaccine has been a significant breakthrough in this field. The live-attenuated VZV vaccine works by boosting pre-existing cell-mediated immunity, providing protection against zoster and PHN. It was initially shown to be efficacious in the Shingles Prevention Study (SPS), a US-based randomized, double-blind, placebo-controlled trial among 38,546 individuals aged 60 years and older, in which it reduced the incidence of zoster by $51 \%$ and PHN by $67 \%$ [68 ] Vaccine effectiveness was subsequently shown in a retrospective cohort study of 75,761 vaccinated individuals insured by the Kaiser Permanente health plan in California, with each matched to three unvaccinated controls; the incidence of zoster was reduced by $55 \%$ among individuals over 60 years of age [69•]. Using population-based data in Canada, the estimated number of 65 -year-old individuals needed to vaccinate to prevent a case of zoster and a case of PHN is $11(90 \%$ CI, 10-13) and 43 (90\% CI, 33-53) [70].

The US Advisory Committee on Immunization Practices (ACIP) recommends routine vaccination among all persons over 60 years of age, excluding patients with major immunosuppression or those with an allergy to any vaccine components [71]. In the context of dermatology clinics, the vaccine should not be given to individuals receiving highdose prednisolone and safety is unknown in relation to biologic drugs, for which the ACIP recommends vaccinating those in target age groups at least 1 month prior to commencement of treatment in the absence of contraindications. A US observational study assessing the use of zoster vaccination in older individuals with inflammatory and 
autoimmune diseases identified 32 patients taking biologic drugs at the time of zoster vaccination; none developed zoster in the subsequent month [72]. Research using Medicare data from 2006 to 2009, currently available in abstract form only, report that among 387 biologic users there were no cases of zoster in the 6 weeks following zoster vaccine administration [73]. Further testing in a clinical trial is required before acceptable safety margins for the use of the live zoster vaccine in patients receiving biologics can be given or specific recommendations on safe intervals for temporary discontinuation of therapy prior to administration. The current literature does not provide clear answers regarding safety in individuals taking other immunosuppressants. The vaccine has also been introduced in Australia. Although the vaccine has not yet been introduced in the United Kingdom, the Joint Committee on Vaccinations and Immunisations (JCVI) has recommended that the zoster vaccine be introduced for immunocompetent individuals aged 70 to 79 years [74].

Vaccine side effects were assessed in $97 \%$ of the study participants in the SPS and the frequency of serious adverse events within 42 days of inoculation was the same in vaccinated (1.4\%) and placebo groups (1.4\%) [68•]. A further substudy of 6616 SPS participants (3345 vaccinated and 3271 placebo) gathered more detailed information on shortterm events and hospitalizations over the entire follow-up period [75]. Local side effects at the inoculation site (eg, erythema, pain, swelling, rash, and pruritus) were more frequently reported in vaccinees $(48 \%)$ than the unvaccinated group (16\%), and having $\geq 1$ inoculation-site adverse event was more common among those aged 60 to 69 years $(56.6 \%)$ compared to individuals aged $\geq 70$ years $(39.2 \%)$. However, events were rarely long lasting or severe. Longer-term followup showed rates of hospitalization and death did not differ between the two groups [75].

Modelling work has suggested that zoster vaccine is costeffective. Using data from the SPS and population-based data from Canada, Brisson et al. [76] suggested the most costeffective strategy was vaccinating adults aged 65 to 75 years, with the main cost benefits being reduced PHN morbidity. One of the main challenges in calculating cost-effectiveness is uncertainty regarding duration of vaccine efficacy, due to the short duration of the SPS trial (mean follow-up of SPS was 3.4 years) [76]. The US Food and Drug Administration have also recently expanded the age range for the zoster vaccine to individuals aged 50 to 59 years on the basis of a large unpublished, multinational, randomized controlled trial showing efficacy of $70 \%$ in terms of reduction of incident zoster; further observational data of vaccine effectiveness are awaited from this age group, and previously discussed ACIP recommendations remain unchanged [77].

Despite the efficacy of the vaccine, its uptake in the US target population has been disappointing. Data from a US household survey from 2007 found $1.9 \%$ of adults aged 60 years and older were vaccinated against zoster, rising in 2008 to $6.7 \%$ [78]. In 2008, rates were lower among Hispanics $(2.1 \%)$ and non-Hispanic blacks $(2.5 \%)$ than nonHispanic whites (7.6\%). Both patient and provider barriers have been suggested as explanations for the low uptake of the zoster vaccine, such as the high vaccine cost, complex methods for reimbursement, and requirement for freezer storage $[79,80]$.

Vaccination coverage levels could be higher if the zoster vaccine was given at the same time as other vaccines. In December 2009, the US Food and Drug Administration stipulated that the zoster vaccine should not be given concurrently with the pneumococcal vaccine, after results from a randomized, double-blind, placebo-controlled trial by the manufacturer on 473 individuals aged $\geq 60$ years found VZV antibody levels were lower among patients receiving concomitant zoster and pneumococcal vaccinations compared to those receiving the zoster vaccine 4 weeks after pneumococcal vaccine (VSV geometric mean titers ratio [concomitant/ non-concomitant] $0.70 ; 95 \%$ CI, 0.61-0.80) [81]. A retrospective cohort study in a US state compared incidence rates of zoster, rather than antibody levels, over a 3 -year period among individuals receiving both vaccines either concomitantly $(n=7187)$ or with at least a 30 -day gap $(n=7179)$. The study found no difference in the incidence of zoster between the groups (HR 1.19; 95\% CI, 0.81-1.74) [82]. The authors suggested that a thorough assessment be undertaken before introducing rules placing barriers on administration of the zoster vaccine, especially considering its low uptake.

\section{Antivirals}

Antivirals are used to limit pain of an acute zoster episode, and some evidence suggests they might also reduce the risk of developing PHN. A recent Cochrane review of five trials comparing acyclovir to placebo and one trial comparing famciclovir to placebo found little difference in prevalence of PHN 6 months after rash onset; however, the meta-analysis was limited to two of the acyclovir trials with the required data (summary RR 1.05; 95\% CI, 0.87-1.27) [83]. This finding partly contrasted previous reviews in which different definitions of PHN were used. These meta-analyses found some evidence of an effect of acyclovir on reducing frequency of PHN [84]. A randomized controlled trial of 419 adults showed a significant reduction in median duration of PHN (although no reduction in PHN incidence) when famciclovir was given using a standard regime [85]. The authors of the Cochrane review suggested further trials be conducted on famciclovir and valacyclovir to clarify their role in reducing duration and 
severity of PHN [83]. These newer agents are, however, significantly more expensive compared to acyclovir and are currently infrequently prescribed.

Antivirals may also be effective in protecting against incidence of zoster among severely immunosuppressed patient groups. For example, a double-blind, placebocontrolled trial of 77 patients undergoing allogenic hematopoietic cell transplant showed that $800 \mathrm{mg}$ of acyclovir, given twice daily for 1 year after the procedure, significantly reduced the risk of zoster (HR 0.16 ; $95 \%$ CI, 0.04-0.74) [86]. With increasing numbers of people becoming immunosuppressed from modern therapies, antiviral use may be proven effective in reducing the incidence of zoster and its associated morbidity in certain high-risk groups.

\section{Conclusions}

The lifetime risk of zoster is high and has important consequences. The greatest breakthroughs in this field have arguably been the development of a highly effective, safe zoster vaccine that has the potential to significantly reduce incidence and morbidity of zoster and PHN, as well as a vaccine to prevent varicella, which could eventually lead to the appreciable reduction of the burden of zoster. Further research focusing on cost and logistics of the zoster vaccine needs attention due to its current low uptake in the United States. Despite the relatively high incidence of zoster in older individuals, relatively little is known about risk factors for zoster, and recent questions have been raised about risks associated with specific co-morbidities. Better understanding of the determinants of zoster could be an important step in preventing herpes zoster episodes and identifying target groups for the vaccine.

Acknowledgement The authors would like to thank Professor Dr Thomas Diepgen at the University of Heidelberg for permission to use the image shown.

Disclosure H.J. Forbes is employed as a research assistant at the London School of Hygiene and Tropical Medicine. S.L. Thomas: none. S.M. Langan has received the National Institute of Health Research (NIHR) Clinician Scientist award and is also funded by the NIHR (which covers research costs, salary, and the salary of H.J. Forbes.)

\section{References}

Papers of particular interest, published recently, have been highlighted as:

\section{- Of importance}

1. - Thomas SL, Hall AJ. What does epidemiology tell us about risk factors for herpes zoster? Lancet Infect Dis. 2004;4(1):26-33. This is a comprehensive review of the incidence and risk factors for zoster.

2. Gnann Jr JW, Whitley RJ. Clinical practice. Herpes zoster. N Engl J Med. 2002;347(5):340-6.

3. Gauthier A, Breuer J, Carrington D, Martin M, Remy V. Epidemiology and cost of herpes zoster and post-herpetic neuralgia in the United Kingdom. Epidemiol Infect. 2009;137(1):38-47.

4. Dworkin RH, Carrington D, Cunningham A, Kost RG, Levin MJ, McKendrick MW, et al. Assessment of pain in herpes zoster: lessons learned from antiviral trials. Antivir Res. 1997;33(2):73-85.

5. Johnson RW, Bouhassira D, Kassianos G, Leplege A, Schmader KE, Weinke T. The impact of herpes zoster and post-herpetic neuralgia on quality-of-life. BMC Med. 2010;8:37.

6. Kang J-H, Sheu J-J, Lin H-C. Increased risk of Guillain-Barre Syndrome following recent herpes zoster: a population-based study across Taiwan. Clin Infect Dis. 2010;51(5):525-30.

7. Gilden DH, Kleinschmidt-DeMasters BK, LaGuardia JJ, Mahalingam R, Cohrs RJ. Neurologic complications of the reactivation of varicella-zoster virus. N Engl J Med. 2000;342 (9):635-45

8. Lin H-C, Chien C-W, Ho J-D. Herpes zoster ophthalmicus and the risk of stroke: a population-based follow-up study. Neurology. 2010;74(10):792-7.

9. Kang J-H, Ho J-D, Chen Y-H, Lin H-C. Increased risk of stroke after a herpes zoster attack: a population-based follow-up study. Stroke. 2009;40(11):3443-8.

10. Insinga RP, Itzler RF, Pellissier JM, Saddier P, Nikas AA. The incidence of herpes zoster in a United States administrative database. J Gen Intern Med. 2005;20(8):748-53.

11. Yawn BP, Saddier P, Wollan PC, St Sauver JL, Kurland MJ, Sy LS. A population-based study of the incidence and complication rates of herpes zoster before zoster vaccine introduction. [Erratum appears in Mayo Clin Proc. 2008 Feb;83(2):255]. Mayo Clin Proc. 2007;82 (11):1341-9.

12. Gonzalez Chiappe S, Sarazin M, Turbelin C, Lasserre A, Pelat C, Bonmarin I, et al. Herpes zoster: burden of disease in France. Vaccine. 2010;28(50):7933-8.

13. Gialloreti LE, Merito M, Pezzotti P, Naldi L, Gatti A, Beillat M, et al. Epidemiology and economic burden of herpes zoster and postherpetic neuralgia in Italy: a retrospective, population-based study. BMC Infect Dis. 2010;10:230.

14. Ultsch B, Siedler A, Rieck T, Reinhold T, Krause G, Wichmann O. Herpes zoster in Germany: quantifying the burden of disease. BMC Infect Dis. 2011;11:173.

15. Morens DM, Bregman DJ, West CM, Greene MH, Mazur MH, Dolin R, et al. An outbreak of varicella-zoster virus-infection among cancer-patients. Ann Intern Med. 1980;93(3):414-9.

16. Melbye M, Grossman RJ, Goedert JJ, Eyster ME, Biggar RJ. Risk of aids after Herpes-Zoster. Lancet. 1987;1(8535):728-31.

17. Pergam SA, Forsberg CW, Boeckh MJ, Maynard C, Limaye AP, Wald A, et al. Herpes Zoster incidence in a multicenter cohort of solid organ transplant recipients. Transpl Infect Dis. 2011;13 (1):15-23.

18. Buchbinder SP, Katz MH, Hessol NA, Liu JY, Omalley PM, Underwood R, et al. Herpes-Zoster and human-immunodeficiencyvirus infection. J Infect Dis. 1992;166(5):1153-6.

19. Morgan D, Mahe C, Malamba S, Okongo M, Mayanja B, Whitworth J. Herpes zoster and HIV-1 infection in a rural Ugandan cohort. AIDS. 2001;15(2):223-9.

20. Gebo KA, Kalyani R, Moore RD, Polydefkis MJ. The incidence of, risk factors for, and sequelae of herpes zoster among HIV patients in the highly active antiretroviral therapy era. Jaids-J Acq Imm Def. 2005;40(2):169-74.

21. Dreiher J, Kresch FS, Comaneshter D, Cohen AD. Risk of Herpes zoster in patients with psoriasis treated with biologic drugs. J Eur Acad Dermatol Venereol. 2011. 
22. Garcia-Doval I, Perez-Zafrilla B, Descalzo MA, Rosello R, Hernandez MV, Gomez-Reino JJ, et al. Incidence and risk of hospitalisation due to shingles and chickenpox in patients with rheumatic diseases treated with TNF antagonists. Ann Rheum Dis. 2010;69(10):1751-5.

23. Strangfeld A, Listing J, Herzer P, Liebhaber A, Rockwitz K, Richter C, et al. Risk of herpes zoster in patients with rheumatoid arthritis treated with anti-TNF-alpha agents. Jama. 2009;301(7):737-44.

24. Serac G, Tubach F, Mariette X, Salmon-Ceron D, Ravaud P, Liote F, et al. Risk of Herpes Zoster in Patients Receiving Anti-TNF-alpha in the Prospective French RATIO Registry. J Invest Dermatol. 2011.

25. Wolfe F, Michaud K, Chakravarty EF. Rates and predictors of herpes zoster in patients with rheumatoid arthritis and non-inflammatory musculoskeletal disorders. Rheumatology (Oxford). 2006;45 (11):1370-5.

26. Smitten AL, Choi HK, Hochberg MC, Suissa S, Simon TA, Testa MA, et al. The risk of herpes zoster in patients with rheumatoid arthritis in the United States and the United Kingdom. Arthritis Rheum. 2007;57(8):1431-8.

27. Yawn BP, Wollan PC, Kurland MJ, St Sauver JL, Saddier P. Herpes zoster recurrences more frequent than previously reported. Mayo Clin Proc. 2011;86(2):88-93.

28. Volpi A, Gatti A, Pica F. Frequency of herpes zoster recurrence. Mayo Clin Proc. 2011;86(6):586. author reply -7 .

29. Hope-Simpson RE. The nature of herpes zoster: a long-term study and a new hypothesis. Proc R Soc Med. 1965;58:9-20.

30. Goldman GS. The case against universal varicella vaccination. Int J Toxicol. 2006;25(5):313-7.

31. Leung J, Harpaz R, Molinari N-A, Jumaan A, Zhou F. Herpes zoster incidence among insured persons in the United States, 1993-2006: evaluation of impact of varicella vaccination. Clin Infect Dis. 2011;52(3):332-40.

32. Jumaan AO, Yu O, Jackson LA, Bohlke K, Galil K, Seward JF. Incidence of herpes zoster, before and after varicella-vaccinationassociated decreases in the incidence of varicella, 1992-2002. J Infect Dis. 2005;191(12):2002-7.

33. Yih WK, Brooks DR, Lett SM, Jumaan AO, Zhang Z, Clements KM, et al. The incidence of varicella and herpes zoster in Massachusetts as measured by the Behavioral Risk Factor Surveillance System (BRFSS) during a period of increasing varicella vaccine coverage, 1998-2003. BMC Publ Health. 2005;5:68.

34. Rimland D, Moanna A. Increasing incidence of herpes zoster among Veterans. Clin Infect Dis. 2010;50(7):1000-5.

35. Russell ML, Schopflocher DP, Svenson L, Virani SN. Secular trends in the epidemiology of shingles in Alberta. Epidemiol Infect. 2007;135(6):908-13.

36. Perez-Farinos N, Ordobas M, Garcia-Fernandez C, Garcia-Comas L, Canellas S, Rodero I, et al. Varicella and herpes zoster in Madrid, based on the Sentinel General Practitioner Network: 1997-2004. BMC Infect Dis. 2007; 7:59.

37. Carville KS, Riddell MA, Kelly HA. A decline in varicella but an uncertain impact on zoster following varicella vaccination in Victoria, Australia. Vaccine. 2010;28(13):2532-8.

38. Castle SC. Clinical relevance of age-related immune dysfunction. Clin Infect Dis. 2000;31(2):578-85.

39. Tyndall MW, Nasio J, Agoki E, Malisa W, Ronald AR, Ndinyaachola $\mathrm{JO}$, et al. Herpes-Zoster as the initial presentation of humanimmunodeficiency-virus Type-I Infection in Kenya. Clin Infect Dis. 1995;21(4):1035-7.

40. Dehne KL, Dhlakama DG, Richter C, Mawadza M, Mcclean D, Huss R. Herpes-Zoster as an indicator of Hiv-infection in Africa. Trop Doct. 1992;22(2):68-70.

41. Gonzaga HF, Jorge MA, Gonzaga LH, Barbosa CA, Chaves MD. Systemic and oral alterations in Brazilian patients with cutaneous herpes zoster. Braz Dent J. 2002;13(1):49-52.
42. Mayanja B, Morgan D, Ross A, Whitworth J. The burden of mucocutaneous conditions and the association with HIV-1 infection in a rural community in Uganda. Trop Med Int Health. 1999;4(5):349-54.

43. Sokal JE, Firat D. Varicella-Zoster infection in Hodgkin's disease: clinical and epidemiological aspects. Am J Med. 1965;39:452-63.

44. Schimpff S, Serpick A, Stoler B, Rumack B, Mellin H, Joseph JM, et al. Varicella-Zoster infection in patients with cancer. Ann Intern Med. 1972;76(2):241-54.

45. Nagasawa K, Yamauchi Y, Tada Y, Kusaba T, Niho Y, Yoshikawa H. High incidence of herpes zoster in patients with systemic lupus erythematosus: an immunological analysis. Ann Rheum Dis. 1990;49(8):630-3.

46. Wung PK, Holbrook JT, Hoffman GS, Tibbs AK, Specks U, Min YI, et al. Herpes zoster in immunocompromised patients: incidence, timing, and risk factors. Am J Med. 2005;118(12):1416.

47. Cupps TR, Silverman GJ, Fauci AS. Herpes zoster in patients with treated Wegener's granulomatosis. A possible role for cyclophosphamide. Am J Med. 1980;69(6):881-5.

48. Hata A, Kuniyoshi M, Ohkusa Y. Risk of Herpes zoster in patients with underlying diseases: a retrospective hospital-based cohort study. Infection 2011.

49. Heymann AD, Chodick G, Karpati T, Kamer L, Kremer E, Green MS, et al. Diabetes as a risk factor for herpes zoster infection: results of a population-based study in Israel. Infection. 2008;36(3):226-30.

50. Yang YW, Chen YH, Wang KH, Wang CY, Lin HW. Risk of herpes zoster among patients with chronic obstructive pulmonary disease: a population-based study. Cmaj. 2011;183(5): E275-80.

51. Wilson JB. Thirty one years of herpes zoster in a rural practice. $\mathrm{Br}$ Med J (Clin Res Ed). 1986;293(6558):1349-51.

52. Thomas SL, Wheeler JG, Hall AJ. Micronutrient intake and the risk of herpes zoster: a case-control study. Int J Epidemiol. 2006;35(2):307-14.

53. Moszczynski P, Zabinski Z, Moszczynski Jr P, Rutowski J, Slowinski S, Tabarowski Z. Immunological findings in cigarette smokers. Toxicol Lett. 2001;118(3):121-7.

54. Cook RT. Alcohol abuse, alcoholism, and damage to the immune system-a review. Alcohol Clin Exp Res. 1998;22(9):1927-42.

55. Schmader K, George LK, Burchett BM, Hamilton JD, Pieper CF. Race and stress in the incidence of herpes zoster in older adults. J Am Geriatr Soc. 1998;46(8):973-7.

56. Kusnecov AW, Rabin BS. Stressor-induced alterations of immune function: mechanisms and issues. Int Arch Allergy Immunol. 1994;105(2):107-21.

57. Schmader K, Studenski S, Macmillan J, Grufferman S, Cohen HJ. Are stressful life events risk-factors for Herpes-Zoster. J Am Geriatr Soc. 1990;38(11):1188-94.

58. Yang YW, Chen YH, Lin HW. Risk of herpes zoster among patients with psychiatric diseases: a population-based study. J Eur Acad Dermatol Venereol. 2011;25(4):447-53.

59. Baba K, Yabuuchi H, Takahashi M, Ogra PL. Increased incidence of herpes zoster in normal children infected with varicella zoster virus during infancy: community-based follow-up study. J Pediatr. 1986;108(3):372-7.

60. Donahue JG, Kieke BA, Gargiullo PM, Jumaan AO, Berger NR, McCauley JS, et al. Herpes zoster and exposure to the varicella zoster virus in an era of varicella vaccination. Am J Public Health. 2010;100(6):1116-22.

61. Cho JW, Shin DH, Lee KS. Polymorphism of the IL-10 gene is associated with susceptibility to herpes zoster in Korea. J Dermatol Sci. 2007;45(3):213-5.

62. Haanpaa M, Nurmikko T, Hurme M. Polymorphism of the IL-10 gene is associated with susceptibility to herpes zoster. Scand J Infect Dis. 2002;34(2):112-4. 
63. Sato-Takeda M, Ihn H, Ohashi J, Tsuchiya N, Satake M, Arita H, et al. The human histocompatibility leukocyte antigen (HLA) haplotype is associated with the onset of postherpetic neuralgia after herpes zoster. Pain. 2004;110(1-2):329-36.

64. Hicks LD, Cook-Norris RH, Mendoza N, Madkan V, Arora A, Tyring SK. Family history as a risk factor for herpes zoster: a casecontrol study. Arch Dermatol. 2008;144(5):603-8.

65. Gatti A, Pica F, Boccia MTY, De Antoni F, Sabato AF, Volpi A. No evidence of family history as a risk factor for herpes zoster in patients with post-herpetic neuralgia. J Med Virol. 2010;82 (6):1007-11.

66. Thomas SL, Wheeler JG, Hall AJ. Case-control study of the effect of mechanical trauma on the risk of herpes zoster. BMJ. 2004;328 (7437):439.

67. Arndt V, Vine MF, Weigle K. Environmental chemical exposures and risk of herpes zoster. Environ Health Perspect. 1999;107(10):835-41.

68. - Oxman MN, Levin MJ, Johnson GR, Schmader KE, Straus SE, Gelb LD, et al. A vaccine to prevent herpes zoster and postherpetic neuralgia in older adults. N Engl J Med. 2005;352(22):2271-84. This article describes the randomised control trial which demonstrated the efficacy of zoster vaccine in preventing zoster and PHN.

69. - Tseng HF, Smith N, Harpaz R, Bialek SR, Sy LS, Jacobsen SJ. Herpes zoster vaccine in older adults and the risk of subsequent herpes zoster disease. Jama. 2011;305(2):160-6. This article describes a large retrospective cohort study that demonstrated zoster vaccine was effective in reducing zoster and PHN.

70. Brisson M. Estimating the number needed to vaccinate to prevent herpes zoster-related disease, health care resource use and mortality. Can J Public Health. 2008;99(5):383-6.

71. Prevention CfDCa. Prevention of Herpes Zoster: Recommendations of the Advisory Committee on Immunization Practices (ACIP). 2008

72. Zhang JE, Delzell ES, Xie FL, Baddley JW, Spettell C, McMahan RM, et al. The use, safety and effectiveness of Herpes Zoster vaccination in individuals with inflammatory and autoimmune diseases. Pharmacoepidem Dr S. 2011;20:S363-4.

73. American College of Rheumatology. Shingles vaccine doesn't increase short term shingles risk in people taking biologics for autoimmune and inflammatory diseases. Press Release. 2011. http://www. rheumatology.org/about/newsroom/2011/2011_ASM_10_shingles_ vaccine.asp. Accessed 1st December 2011.

74. JCVI. Joint Committee on Vaccination and Immunisation Statement on varicella and herpes zoster vaccines. 2010.
75. Simberkoff MS, Arbeit RD, Johnson GR, Oxman MN, Boardman KD, Williams HM, et al. Safety of herpes zoster vaccine in the shingles prevention study: a randomized trial. Ann Intern Med. 2010;152 (9):545-54.

76. Brisson M, Pellissier JM, Camden S, Quach C, De Wals P. The potential cost-effectiveness of vaccination against herpes zoster and post-herpetic neuralgia. Hum. 2008;4(3):238-45.

77. Update on herpes zoster vaccine: licensure for persons aged 50 through 59 years. MMWR Morb Mortal Wkly Rep. 2011;60:1528.

78. Lu P-j, Euler GL, Harpaz R. Herpes zoster vaccination among adults aged 60 years and older, in the U.S., 2008. Am J Prev Med. 2011;40(2):e1-6.

79. JS S, GL E. Vaccination coverage estimates from the National Health Interview Survey: United States, 2008

80. Hurley LP, Lindley MC, Harpaz R, Stokley S, Daley MF, Crane LA, et al. Barriers to the use of Herpes Zoster vaccine. Ann Intern Med. 2010;152(9):555.

81. MacIntyre CR, Egerton T, McCaughey M, Parrino J, Campbell $\mathrm{BV}, \mathrm{Su} \mathrm{SC}$, et al. Concomitant administration of zoster and pneumococcal vaccines in adults $>/=60$ years old. Hum Vaccin. 2010;6 (11):894-902.

82. Tseng HF, Smith N, Sy LS, Jacobsen SJ. Evaluation of the incidence of herpes zoster after concomitant administration of zoster vaccine and polysaccharide pneumococcal vaccine. Vaccine. 2011;29(20):3628-32.

83. Li QF, Chen N, Yang J, Zhou MK, Zhou D, Zhang QW, et al. Antiviral treatment for preventing postherpetic neuralgia. Cochrane Db Syst Rev. 2009(2).

84. Wood MJ, Kay R, Dworkin RH, Soong SJ, Whitley RJ. Oral acyclovir therapy accelerates pain resolution in patients with herpes zoster: a meta-analysis of placebo-controlled trials. Clin Infect Dis. 1996;22(2):341-7.

85. Tyring S, Barbarash RA, Nahlik JE, Cunningham A, Marley J, Heng M, et al. Famciclovir for the treatment of acute herpes zoster: effects on acute disease and postherpetic neuralgia. A randomized, double-blind, placebo-controlled trial. Collaborative Famciclovir Herpes Zoster Study Group. Ann Intern Med. 1995;123(2):89-96.

86. Boeckh M, Kim HW, Flowers ME, Meyers JD, Bowden RA. Long-term acyclovir for prevention of varicella zoster virus disease after allogeneic hematopoietic cell transplantation-a randomized double-blind placebo-controlled study. Blood. 2006;107(5):1800-5. 